\title{
A UTILIZAÇÃO DO SOFTWARE CONSTRUFIG3D NO PROCESSO DE CONSTRUÇÃO DO SIGNIFICADO DA RELAÇÃO DE EULER
}

Janaína Veiga Carvalho

\author{
Docente do Programa de Mestrado Profissional em Educação Matemática \\ Universidade Severino Sombra - Vassouras - RJ \\ janainavcarvalho@gmail.com \\ Carlos Vitor de Alencar Carvalho \\ Docente do Programa de Mestrado Profissional em Educação Matemática \\ Universidade Severino Sombra - Vassouras - RJ \\ cvitorc@gmail.com \\ Lucia Maria Aversa Villela \\ Docente do Programa de Mestrado Profissional em Educação Matemática \\ Universidade Severino Sombra - Vassouras - RJ \\ luciavillela@globo.com
}

\section{Resumo}

Este trabalho apresenta a utilização e avaliação do sistema computacional CONSTRUFIG3D para apoio na construção do significado da relação de Euler. Numa análise rápida acerca do ensino tradicional, percebem-se ações que contrariam a proposta de educação baseada na construção do conhecimento e de como acontece o desenvolvimento cognitivo do aluno. Face à importância e à relação que a Matemática, como ciência, sempre teve com as tecnologias e ao fascínio provocado pelo computador entre os jovens, urge uma profunda reflexão na proposta de que uso do computador como ferramenta pedagógica e suas implicações positivas que favorecem uma possibilidade de alteração deste cenário.

Palavras-chave: Software Educativo, Educação Matemática, Geometria Plana e Espacial

Usage and evaluation of the Computational System CONSTRUFIG3D for the teaching of geometry

\begin{abstract}
This work presents the usage and evaluation of the computational system CONSTRUFIG3D for support in the construction of the meaning of the relationship of Euler. In a fast analysis concerning the traditional teaching, they are noticed actions that thwart the proposal of set education in the construction of the knowledge and of as the student's cognitive development happens. Face to the importance and the relationship that the Mathematics, as science, always had with the technologies and to the fascination provoked by the computer among the youths, it urges a deep reflection in the proposal that use of the computer as pedagogic tool and its positive implications that favor a possibility of alteration of this scenery.
\end{abstract}

Key-Words: Educational Software, Mathematic Education, 2D and 3D geometries 


\section{Introdução}

O uso do computador no cotidiano está cada vez mais frequente. Esta realidade força os educadores e as escolas a trazer este novo recurso para dentro das suas dependências, dando-lhe um uso mais efetivo. Desta forma, temos cada vez mais estabelecimentos de ensino equipadas com laboratórios de informática, porém existe uma questão importante: como utilizar estes novos ambientes para auxiliar na construção do conhecimento dos nossos alunos?

Os educadores que tomam para si este novo desafio devem procurar respostas a vários questionamentos antes de levar seus alunos para estes tais laboratórios, como por exemplo, que tópico da disciplina abordarei associando o uso do computador?; Para este tópico, qual o programa mais adequado a ser utilizado com a minha turma?; Como desenvolverei a atividade no laboratório?; Quais vantagens esta atividade trará para a construção do conhecimento? Os educadores que estão dispostos a pensar sobre tais aspectos começam a entrar na zona de risco descrita em Borba (2005), onde nem todos os aspectos são previsíveis e controláveis. Ao entrar nesta zona de risco o educador deve refletir sobre o seu modo de ensinar. Regina Célia Haidt diz que:

(...) o emprego do computador no processo pedagógico, assim como o uso de qualquer tecnologia, exige do educador uma reflexão crítica. Refletir criticamente sobre o valor pedagógico da informática significa também refletir sobre as transformações da escola e repensar o futuro da educação (HAIDT, 2001).

O educador deve sempre refletir sobre a prática pedagógica e, diante de tantos questionamentos, esta necessidade se coloca de forma incisiva. Buscando contribuir para este procedimento um grupo de professores que atuam na Universidade Severino Sombra, em cursos de graduação e pós-graduação stricto sensu (Mestrado Profissional em Educação Matemática), desenvolvem investigações articuladas a duas linhas de pesquisa - a) Metodologias e Tecnologias de Informação Aplicadas ao Ensino de Matemática; b) Organização Curricular em Matemática e Formação de Professores.

Como resultados destes estudos foram realizadas oficinas com professores de escolas de educação básica da região onde se localiza a Universidade Vassouras/Estado do Rio de Janeiro. Estas oficinas buscam aplicar e investigar, além de recursos manipuláveis usuais, o uso de um determinado software no ensino da Matemática. Neste trabalho apresentamos:

1. Processo de desenvolvimento do sistema computacional CONSTRUFIG3D para apoio ao ensino da geometria plana e espacial;

2. Proposta pedagógica para a utilização deste programa na construção do significado da relação de Euler;

3. Reflexão sobre as observações realizadas durante as oficinas.

Desse modo, o restante deste artigo está organizado da seguinte forma: primeiramente tem-se a apresentação do processo de desenvolvimento do sistema computacional CONSTRUFIG3D para apoio ao ensino da geometria plana e espacial. Depois é descrita a proposta pedagógica trabalhada na oficina de formação de professores e finalmente as reflexões sobre os resultados obtidos e as considerações finais do trabalho.

\section{O CONSTRUFIG3D}

Os computadores, durante os últimos dez anos, são considerados como um dos fatores promissores que influenciaram a educação, inovando-a ou corrigindo seus 
rumos. Uma das formas de utilizar o computador como apoio ao ensino é através de um sistema computacional educativo que tem o objetivo de melhorar o processo ensinoaprendizagem de um conteúdo ou assunto educacional. Ele pode ser o elo de ligação entre os professores e os alunos e o seu o objetivo é ajudar a melhorar a prática docente. Além disso, ele pode estimular um ambiente colaborativo entre professor-estudante e estudante-estudante.

É importante ressaltar que o uso dos softwares educativos não deve ser considerado como uma máquina de ensinar, ma sim como uma ferramenta auxiliar que permita a reflexão e construção de ideias. Eles medeiam à prática pedagógica oferecendo desafios importantes voltados à produção intelectual, em que o aluno passa a ser produtor de conhecimento e a ação docente dá lugar à relação dialógica que permite ao professor e ao aluno aprender a aprender, num processo coletivo para a produção do conhecimento (PAIVA et al, 2008).

O CONSTRUFIG3D surgiu em 2005 na Universidade Severino Sombra (USS), localizada em Vassouras ${ }^{1}$, através da orientação de um aluno do curso de Sistemas de Informação pelo primeiro e segundo autores deste artigo. A ideia para a proposta do programa considerou duas características iniciais: a) parecer um jogo, propiciando ambiente de investigação lúdico e significativo; b) apresentar, como enredo, um conteúdo matemático (no caso, a geometria). Na geometria optou-se por trabalhar com a geometria plana e a geometria espacial, ou seja, montar figuras espaciais a partir de figuras planas. Os desenvolvedores do CONSTRUFIG3D, precisavam então responder algumas perguntas:

a) Quais e quantas figuras planas poderiam ser utilizadas pelos usuários para tentar montar uma figura espacial?

b) A ordem da inserção das figuras deveria influenciar na construção da figura espacial?

Para o primeiro questionamento optou-se, pelas figuras: círculo, triângulo e retângulo (qualquer e o quadrado), na quantidade mínima de três e no máximo seis. Para facilitar a visualização por parte do usuário, cada figura plana é desenhada com uma cor diferente como mostra a Figura 1.

Para o segundo questionamento optou-se pela forma livre de escolha das figuras planas, ou seja, a ordem de inserção não deve influenciar na construção. Assim, o sistema foi preparado para considerar todos os casos selecionados pelo usuário em qualquer ordem. Por exemplo, para montar um cilindro o aluno pode escolher: um retângulo e dois círculos; um círculo, um retângulo e um círculo; dois círculos e um retângulo (Mendes, 2007). A Figura 2 apresenta alguns exemplos.

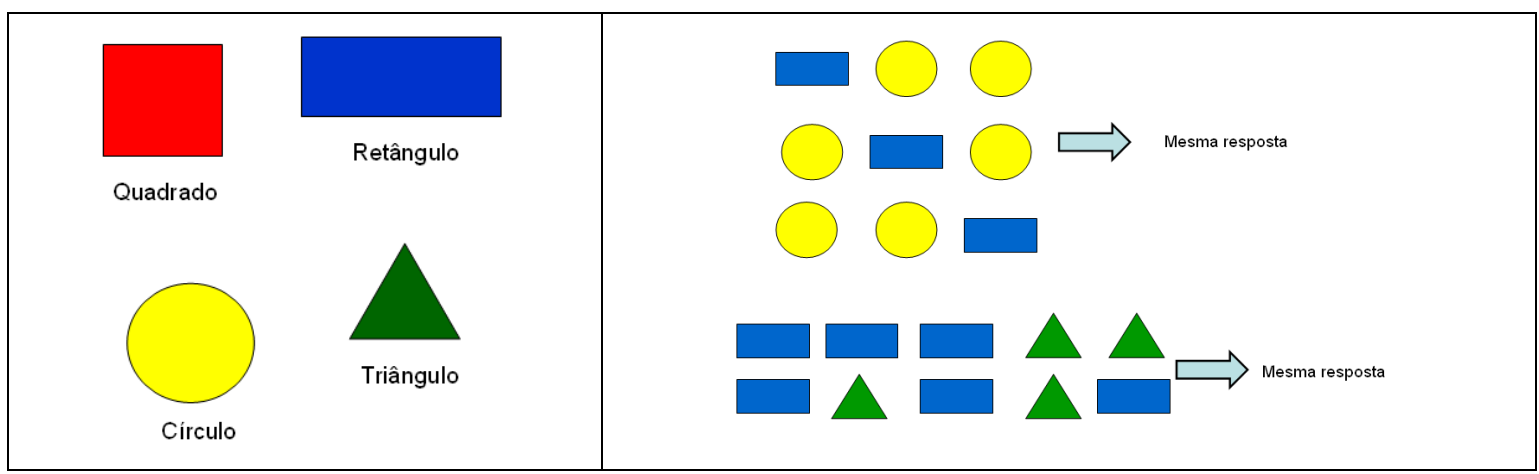

\footnotetext{
${ }^{1}$ Cidade histórica e universitária localizada no interior do Estado do Rio de Janeiro - Brasil - há 119 km da capital.
}

V. $8 \mathrm{~N}^{\mathrm{o}} 3$, dezembro, 2010 
Figura 1 - Definição das figuras planas.
Figura 2 - Exemplos de seqüências diferentes que chegam à uma mesma figura espacial.

Se a quantidade e as figuras planas selecionadas forem coerentes, uma figura espacial será montada e visualizada. Resumidamente, o usuário deve seguir as seguintes etapas:

a. Selecionar o número de 3 a 6 peças, conforme quantidade de faces da figura espacial desejada;

b. Selecionar as figuras planas que compõem a figura espacial. Na área de desenho 2D serão visualizadas as figuras conforma seleção;

c. Em seguida acionar o botão montar;

d. Se a sequência e a quantidade for correta aparecerá a figura desejada na área de desenho 3D e uma mensagem associada a montagem da figura espacial. Caso contrário, uma mensagem aparecerá avisando que a figura não pode ser montada.

A interface inicial do sistema desenvolvido pode ser visualizada na Figura 3. Pode-se identificar uma área 2D e 3D para a visualização das figuras planas e espaciais respectivamente além de uma barra de ferramentas. A interface em que adicionado a funcionalidade de observação de vértices, arestas e faces é apresentada na Figura 4. A interface atual, em que foi adicionada uma área para visualização da planificação, é apresentada na Figura 5.
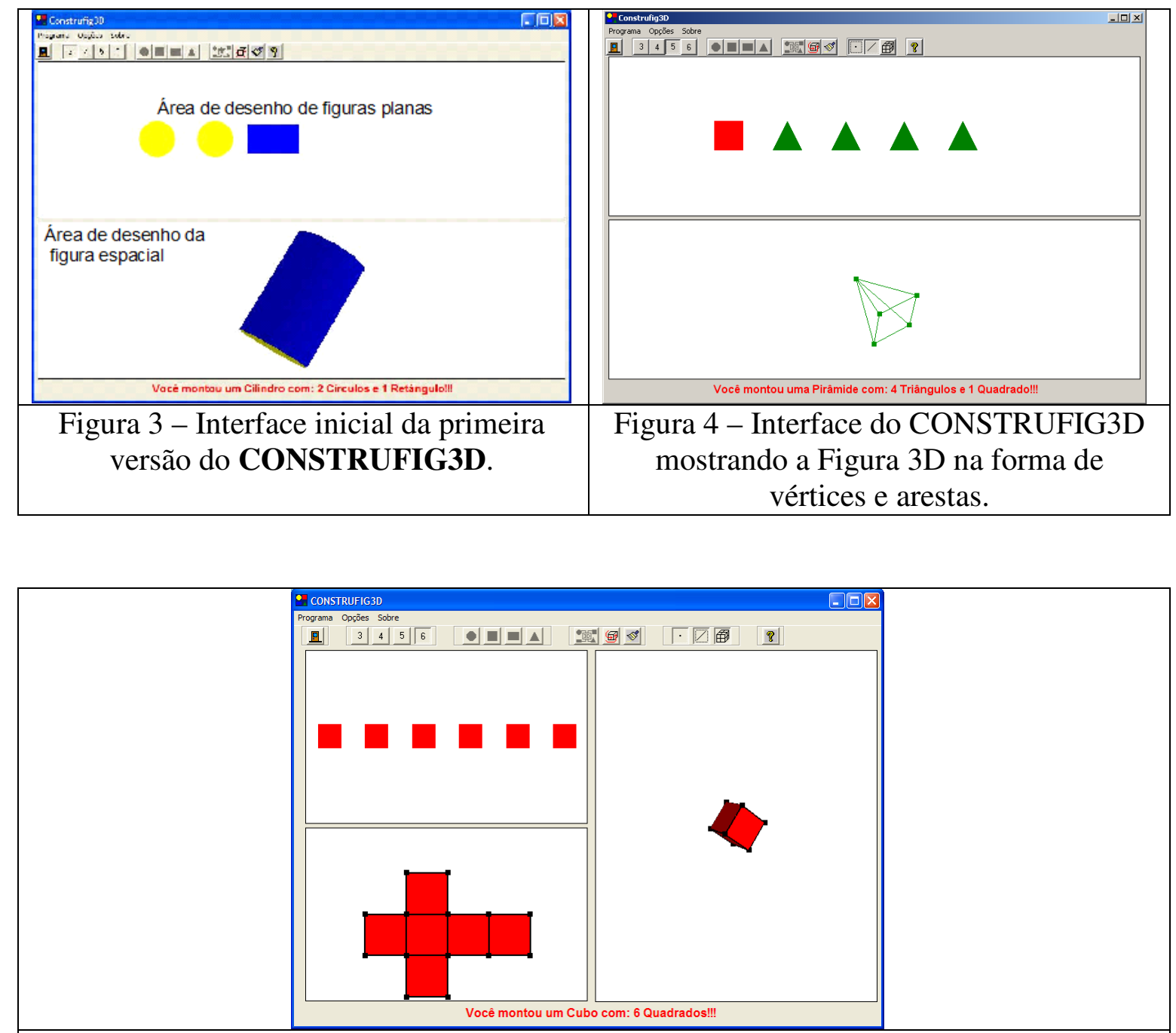

Figura 5 - Figuras planas escolhidas pelo usuário e o cubo montado e visualizado na 
área 3D, bem a sua planificação com as funcionalidades vértice, aresta e face ativada.

As funcionalidades oferecidas pelo CONSTRUFIG3D e o processo de evolução do software podem ser obtido em Carvalho (2009).

\section{Proposta pedagógica para a utilização deste programa na construção do significado da relação de Euler}

O sistema vem sendo utilizado em uma oficina no laboratório de Informática onde a dinâmica tem compreendido dois módulos: o primeiro com uma atividade prática e o segundo com a utilização do CONSTRUFIG3D. A ideia principal da atividade prática é possibilitar aos professores a manipulação de figuras espaciais, a manipulação e construção de figuras espaciais a partir de figuras planas, antes da utilização deste sistema. Assim, as etapas das oficinas são:

a) promover no grupo uma discussão para observar as formas de diferentes caixas de papelão ou objetos variados, agrupando-os de maneira que tenham a mesma forma. Dessa forma são identificadas propriedades dessas caixas, tais como quantidade de vértices $(\mathrm{V})$, arestas $(\mathrm{A})$ e faces $(\mathrm{F})$. Anotar estas informações em uma planilha, para tentar encontrar um padrão;

b) os participantes da oficina devem ser divididos, em sub-grupos (quatro integrantes em cada subgrupo, por exemplo). Cada grupo receberá um kit de montagem (4 círculos, 10 retângulos, 10 quadrados, 10 triângulos e uma fita durex). Durante vinte e cinco minutos cada subgrupo tentará montar a maior quantidade de figuras espaciais.

c) Após esta etapa cada grupo irá quantificar a quantidade de vértices, arestas e faces das figuras espaciais confeccionadas. Anotar estas informações, para tentar encontrar um padrão;

d) Analisando as informações anotadas, os ministrantes devem estimular os participantes a descobrir uma relação entre a quantidade de vértices, arestas e faces. Ao longo dessas falas, ao se dar continuidade ao preenchimento dos dados na planilha, normalmente salta aos olhos a relação existente entre F, V e A, em cada linha: $\mathrm{F}+\mathrm{V}=\mathrm{A}+2$.

e) Os ministrantes apresentam um breve histórico, localizando Euler como um grande matemático do século XVIII. Além disso, caso ainda não tenha ocorrido, provoca-se o debate com relação às figuras espaciais: são eulerianas ou não-eulerianas? Os sólidos obtidos são convexos ou não-convexos?

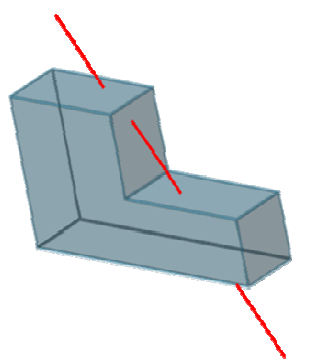

Figura 6

Poliedro não-convexo

$$
\mathrm{F}=8 \underset{\text { é euleriano }}{\mathrm{V}=12 \mathrm{~A}=18}
$$

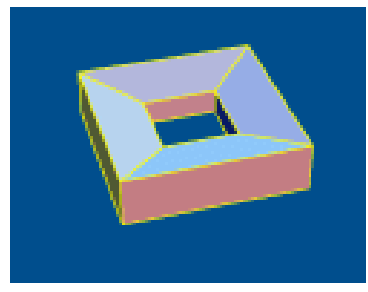

Figura 7

Poliedro não-convexo

$$
\begin{gathered}
\mathrm{F}=16 \mathrm{~V}=16 \quad \mathrm{~A}=32 \\
\text { é não-euleriano }
\end{gathered}
$$


f) Reproduzir no CONSTRUFIG3D, em 20 minutos, o processo de montagem das suas figuras espaciais. Verificar se as figuras elaboradas são eulerianas ou não.

g) Análise da atividade prática desenvolvida.

\section{Reflexão sobre as observações realizadas durante as oficinas}

Está proposta foi experimentada em três oficinas com públicos distintos. A primeira aconteceu no distrito de tecnologia educacional RJ19- Vassouras (DTERJ19Vassouras), no CIEP Padre Salésio Schimid, em junho de 2010, contando com a participação de 8 professores (Figura 8, Figura 9 e Figura 10). A segunda aconteceu também no DTERJ19, no CIEP 298 - Manuel Duarte, em agosto de 2010, contando com a participação de 6 professores. Estas duas surgiram da demanda da coordenadora do DTERJ19 ao Mestrado Profissional em Educação Matemática da USS, pela realização de formação continuada para os professores que envolvesse a questão da TIC.

A terceira oficina estava inserida em projeto de pesquisa intitulado "INCLUSÃO DIGITAL E INTERVENÇÕES PEDAGÓGICAS: ressignificando práticas de leitura e ensino da matemática". Este projeto visa a melhoria do ensino na Escola a partir da discussão sobre as diferentes linguagens como práticas sociais, envolvendo a linguagem matemática e os discursos verbais e não-verbais, articuladas às Tecnologias de Informação e Comunicação com abordagem lúdica e contextualizada, com as características do Município de Vassouras e do bairro/distrito Itakamosi (RJ), onde se localiza o Colégio Estadual Antônio Jesus Gomes. A escola atende do sexto ano do ensino fundamental ao terceiro ano do ensino médio. A escolha do estabelecimento justifica-se por termos observado, em reunião com os gestores em visita à escola, preocupações com a escolaridade dos alunos e com as práticas pedagógicas adotadas pelos professores. Em conversa com a direção da Escola, verificamos que "a sala de aula, de um modo formal ainda prevalece no cotidiano escolar. No entanto, aos poucos esta prática está sendo repensada, através de recursos tecnológicos e/ ou simples jogos como dama, baralho, dominó ou xadrez". Observamos a preocupação da equipe gestora com a necessidade de estimular a aprendizagem através da emoção, da surpresa, do jogo, do ambiente prazeroso, da integração, do suspense, de valores éticos como a solidariedade, a tolerância, a amizade, o respeito etc.

A oficina na escola realizada em setembro de 2010, contou com a participação de 8 professores e uma aluna. Visava uma das metas do projeto que é a observação participante em oficinas de formação continuada dos professores com intuito de apresentar propostas pedagógicas com o uso de softwares educacionais (Figura 11, Figura 12 e Figura 13).

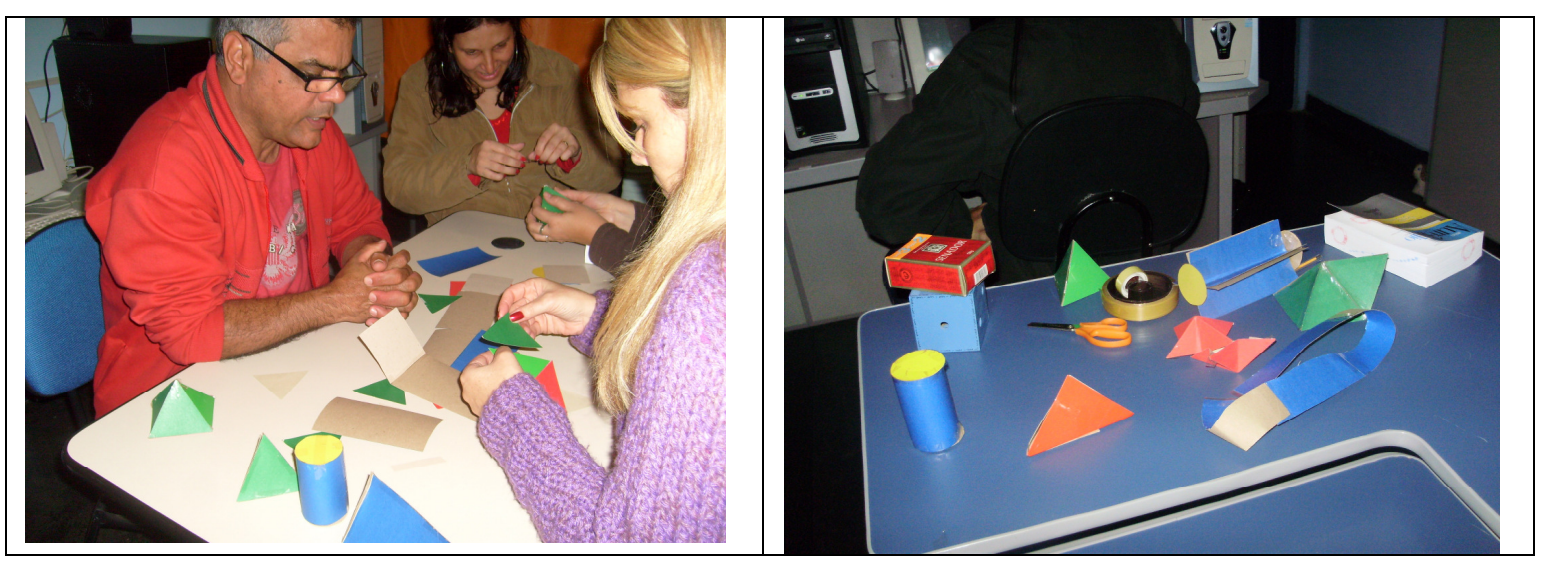

V. $8 \mathrm{~N}^{\mathrm{o}} 3$, dezembro, 2010 
Figura 8 - Professores montando figuras geométricas com cartões de papelão (oficina 1).
Figura 9 - Figuras montadas pelos professores (oficina 1).

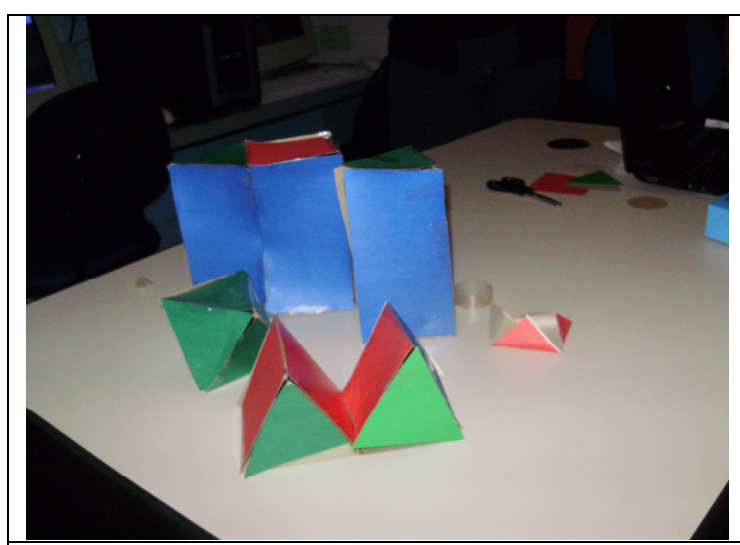

Figura 10 - Figuras montadas pelos professores (oficina 1).

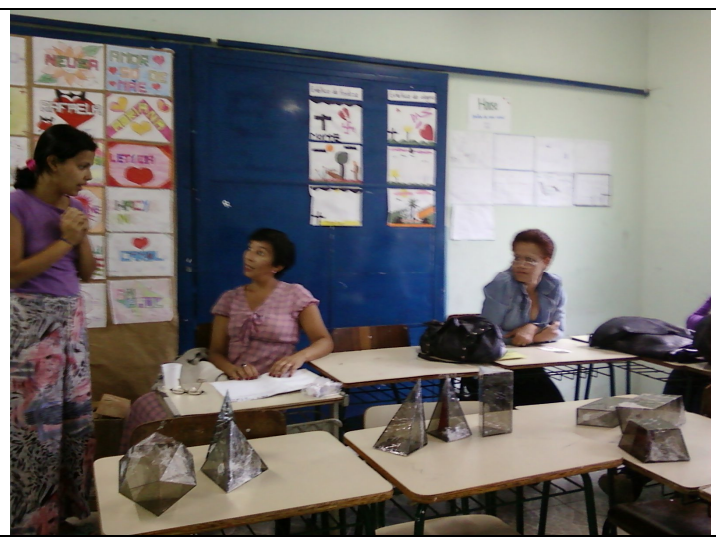

Figura 11 - Professores participando da oficina na escola em Itakamosi (oficina 3)

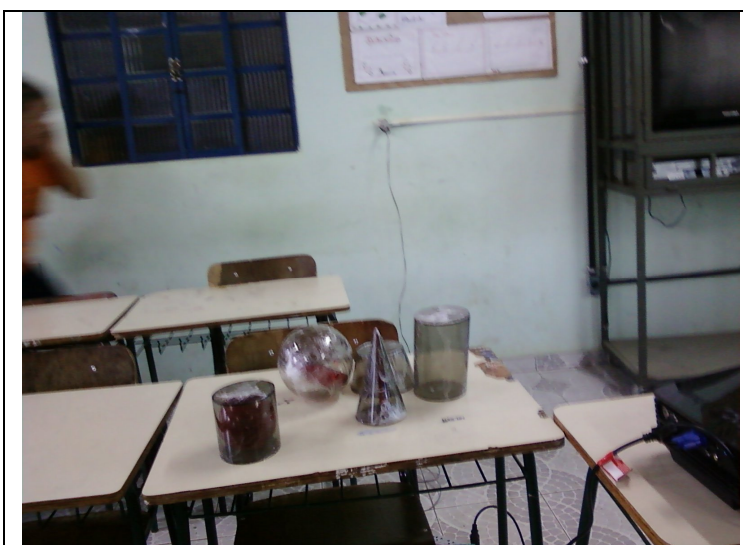

Figura 12 - Sólidos de acrílico utilizados na oficina (oficina 3).

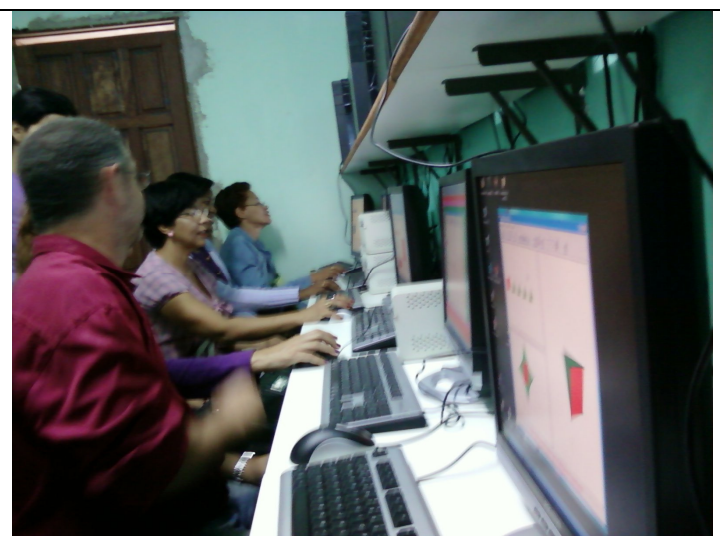

Figura 13 - Utilização do software CONSTRUFIG3D na escola em Itakamosi (oficina 3).

Na primeira oficina, durante a primeira etapa surgiram questões envolvendo os conceitos de semelhança e forma, observação de figuras convexas e figuras nãoconvexas e foram trabalhadas as noções de vértice, aresta e face. Havia professoras da educação infantil, do primeiro segmento do ensino fundamental e professores com formação em matemática. No momento de montar as figuras, surgiram formas geométricas variadas convexas e não-convexas. Para todas as figuras construídas, foram contabilizadas a quantidade de vértices, arestas e faces. Foi neste momento que os participantes das oficinas verbalizaram uma relação entre os três elementos. Os professores de matemática já conheciam a relação e, durante esta etapa de construção, preocuparam-se em nomear as figuras construídas (prisma, pirâmide, hexaedro, etc). $\mathrm{O}$ CONSTRUFIG3D foi utilizado para a construção das figuras ocorrendo situações de figuras que não estavam disponíveis no software. Foi apresentado para os participantes 
o software Uma Pletora de Poliedros ${ }^{2}$, do Professor Humberto José Bortolossi, onde existe uma grande variedade de poliedros a serem visualizados.

$\mathrm{Na}$ segunda oficina, também surgiram questões sobre o significado das palavras forma e semelhança: ter a mesma forma é o mesmo que serem figuras semelhantes? Nesta oficina os participantes eram todos professores de matemática e várias reflexões sobre a maneira de ensinar a geometria e os receios que esta parte da matemática causa aos professores foram trazidas pelo professores. Tal como ocorrera na primeira oficina, também foram criadas figuras não convexas. Percebeu-se nesta oficina uma predisposição dos participantes a construírem figuras já conhecidas da matemática e novamente o interesse de nomear todas as figuras.. Foram contabilizadas a quantidade de vértices, arestas e faces também para todas as figuras. Alguns professores de matemática já conheciam a relação e outros a diziam já esquecida. Consideramos também relevante o interesse em perceberem que a relação de Euler pode ser verificada também em alguns sólidos não-convexos. O CONSTRUFIG3D foi explorado por mais tempo nesta oficina e de forma mais livre pelos participantes. Não houve a preocupação de montar todas as figuras. O site do Prof Bortolossi - Uma Pletora de Poliedros - foi novamente visitado.

$\mathrm{Na}$ terceira oficina tivemos um público participante mais heterogêneo: eram os professores de todas as disciplinas da escola e uma aluna de segunda série do ensino médio. A dinâmica da oficina foi adaptada, utilizado um kit de sólidos geométricos em acrílico, que havia acabado de chegar à escola ${ }^{3}$. Foi solicitado que se agrupasse os sólidos geométricos de mesma forma e, foi analisado para cada sólido a quantidade de vértices, arestas e faces. Nesta oficina, como o tempo disponível foi menor, não foi realizado a etapa de montagem de figuras. Os participantes usaram as observações realizadas nos sólidos de acrílicos e anotadas na planilha para obter a relação de Euler. Nesta oficina foi observada maior empolgação no uso do CONSTRUFIG3D. Professores de matemática e a professora de artes manifestaram interesse em utilizá-lo em suas aulas.

\section{Considerações Finais}

O CONSTRUFIG3D é um programa educacional, que propõe ao aluno o trabalho do conteúdo matemático de forma exploratória de acordo com os ideais propostos pela teoria construtivista. Cada aluno tem o seu próprio "tempo" e "espaço" de construção de conhecimento. Associado à escolha do software educacional escolhido, devemos pensar como trabalhar como este programa. A proposta pedagógica tem importância fundamental no sucesso do uso do computador em aula, mas temos que ter clareza que este é apenas mais um recurso a ser utilizado.

Neste trabalho sugerimos um software e a proposta pedagógica para trabalhar tópicos ligados a Geometria Plana e Espacial. Futuramente, pretendemos aplicar esta proposta pedagógica em sala de aula.

\section{Agradecimentos}

\footnotetext{
Este material, que estava disponível em http://www.uff.br/cdme/pdp/pdp-html/pdp-br.html, no momento da elaboração deste artigo não está acessível.

Fora comprado com verba da FAPERJ, via projeto pesquisa intitulado "INCLUSÃO DIGITAL E INTERVENÇÕES PEDAGÓGICAS: ressignificando práticas de leitura e ensino da matemática"
}

V. $8 \mathrm{~N}^{\mathrm{o}} 3$, dezembro, 2010 
A primeira autora agradece à FAPERJ pelo apoio financeiro através do programa "apoio à melhoria do ensino em escolas sediadas no estado do Rio de Janeiro - 2009". O segundo autor agradece ao CNPQ pelo apoio financeiro através da Bolsa de Produtividade em Desenvolvimento Tecnológico e Extensão Inovadora - DT.

\section{. Referências Bibliográficas}

BORBA, M. C. e PENTEADO, M. G., Informática e Educação Matemática, 3.ed., 1.reimp., Belo Horizonte: Editora Autêntica - Coleção Tendências em Educação Matemática, 2005.

CARVAlho, J. V., CARVAlho, C. V. de A., PAiva, A. M. S. de, Sá, I. P. de Implicações de um software educacional na formação de professores. Revista electrónica de investigación en educación en ciencias (Online). , v.4, p.28 - 36, 2009.

HAIDT, R. C. C. Curso de didática Geral - Capítulo 12 - A informática na Educação, São Paulo: Editora Ática - Série Educação, 2001.

MENDES, J. L. de S., CARVAlHO, C. V. A., CARVAlHO, J. V. (2007) CONSTRUFIG3D: Uma Ferramenta Computacional para apoio ao ensino da Geometria Plana e Espacial. RENOTE - Revista Novas Tecnologias na Educação. , v.5, p.1/10 - 10 .

PAiva, A. M. S., CARVAlhO, J. V., CARVAlho, C. V. A., PORTO, I da P. G., A integração da TIC na Escola Básica: Questões para Avaliação, Revista Eletrônica do Centro de Ciências Exatas, Tecnológicas e da Natureza da Universidade Severino Sombra - HTTP://www.uss.br/revistateccen, ano 1, volume 1, 2008. 